\title{
Special Issue on Migration and Remittances: An Introductory Note
}

Hiranya K. Nath

Sam Houston State University - Huntsville, TX

\section{Introduction}

The history of humankind has been the history of constant movements of people across natural as well as man-made boundaries. The adventure of discovery, the search for a better life in the face of destitution and misery caused by natural and man-made calamities, and above all, an indomitable human spirit have pushed people around over the centuries. The progress of human civilization is inconceivable without these movements. Therefore, migration has been an intriguing area of study for researchers from a wide range of disciplines: history, geography, anthropology, sociology, psychology, and economics.

According to the United Nations estimate, the total stock of immigrants in the world was 190.6 million or $3 \%$ of the world population in 2005 . The top 10 destination countries for international migration include the United States, Russia, Germany, Ukraine, France, Saudi Arabia, Canada, India, the United Kingdom, and Spain. The top 10 emigration countries are: Mexico, Russia, India, China, Ukraine, Bangladesh, Turkey, the United Kingdom, Germany, and Kazakhstan. ${ }^{1}$ Note that both groups include developed as well as developing countries. Furthermore, countries such as Russia, Germany, Ukraine, India, and the United Kingdom, have experienced large-scale in-migration as well as out-migration. These movements of people across national boundaries have important impact on the society, polity, and economy of both home and host country.

One of the most significant developments related to international migration, especially from developing to developed countries, is that the migrants transfer a large sum of money to their family and friends back home. According to World Bank (2008), the estimated total of officially recorded remittance inflows reached USD 317.7 billion in 2007. This amount represents a three-fold increase from USD 101.6 billion in 1995. The developing countries received a total of USD 239.7 billion or about $75 \%$ of the amount in 2007 . However, the actual size of remittances, including unrecorded flows through formal and informal channels, is much larger. The top 10 remittance recipient countries in 2007 are: India, China, Mexico, Philippines, France, Spain, Belgium, the United Kingdom, Germany, and Romania. The top remittance sending countries include the United 
States, Saudi Arabia, Switzerland, Germany, Russian Federation, Spain, Italy, Luxembourg, Netherlands, and Malaysia. These remittances have been a major source of a wide range of benefits in the recipient countries. The recent surge in world-wide remittance flows has attracted the attention of the researchers towards understanding the causes and consequences of these transfers. Given the amount of money involved and their potential impact, this research agenda has important policy implications.

This special issue of the Journal of Business Strategies includes six research articles that address various issues related to migration and remittances with a focus on Latin America. This selection has been made out of a pool of papers presented at the Conference on Regional Trade Agreements, Migration, and Remittances with Special Focus on CAFTA and Latin America, organized in Spring 2008 by the Department of Economics and International Business, in collaboration with Gibson D. Lewis Center for Business Research and Economic Development at the College of Business Administration, Sam Houston State University. The research findings presented in these articles have important implications for public policies and business strategies in the U.S., the host of the largest immigrant population, as well as in the home countries of these immigrants.

There will be another special issue of the journal, scheduled to be published in Spring 2010, that will include research articles primarily concerned with regional trade agreements and a few additional topics related to remittances. The selection is being made out of the same pool of papers as mentioned above.

\section{Migration}

The first three articles in this issue deal with three important topics related to international migration from Latin America. While Cárdenas, Di Maro, and Sorkin demonstrate that migration has positive net effects on the well-being of family members of migrants in home countries, Orrenius and Nicholson highlight the negative effects of immigration, particularly of illegal immigration, in the host country. Molina and Jewell focus on the remigration decisions of the Mexican illegal immigrants in the United States.

\section{A home country perspective}

Cárdenas et al. examine how migration affects the well-being of the family members left behind by the migrants in their respective home countries in Latin America and the Caribbean. This paper contributes to the existing literature on the 
relationship between migration and well-being by analyzing the effects of migration on "subjective measures of well-being".

The primary finding of this investigation, based on micro-level data from the Gallup World Poll and Latinobarómetro, is that in most cases migration enhances the well-being of the migrant-sending families. Controlling for remittance-augmented income, often recognized as the strongest direct channel of positive impact of migration on well-being through higher level of consumption, the study finds that households with migrant family members are more satisfied than households with no family members abroad. The authors argue that this additional positive impact can be attributed to the role of remittances as an insurance to consumption against income shock, a channel that has also been recognized in the literature. Another channel uncovered by the analysis is that remittances are often spent on items such as education or health that make a greater direct contribution to life satisfaction (well-being). Furthermore, the authors argue that migration might affect satisfaction through changes in expectations. In particular, the observation of a better life for the migrant family member might increase hopes among other members who are left behind for their own future. However, the study finds that those households that are nutritionally insecure, and hence the most vulnerable, are made worse off by migration. This result is at odds with the pro-poor effects of migration found in other studies and leads the authors to suggest that the social safety net in poor areas, particularly those with heavy outflows of migrants, should be strengthened. This study also adds to the current literature by making clear distinction between three types of insecurities: nutritional, personal, and employment, among the migrantsending families.

\section{A host country perspective}

Orrenius and Nicholson, in their article, present a host country perspective on immigration into the U.S. ${ }^{3}$ Recounting the changes in the nature of immigration over the 20th century, they observe two important recent trends among the immigrants in the U.S. First, the education distribution of foreign-born workers has become highly bimodal: either they are highly educated or they have very little education. However, the authors contend that this pattern complements the educational pattern among the native workers who are overwhelmingly concentrated in the middle of education distribution. Second, illegal immigration, particularly from Mexico, has grown quickly in recent years and has come to constitute a significant proportion of the foreign-born population. They ascribe this rise in illegal immigra- 
tion to a combination of factors: changes in the U.S. immigration policy over the years and relative economic conditions in Mexico and the U.S.

Although the article recognizes that global re-allocation of workers through migration from developing to developed countries benefits the world as a whole, it argues that the effects of migration on host-country natives are far less positive. In general, immigration has a positive effect on employment and output growth and benefits the native-born consumers by lowering relative prices of goods and services, and the investors, business owners, and landowners by increasing the returns on capital and land. However, there are at least two ways in which it affects the natives adversely. First, the gains from immigration disproportionately benefit investors, mid- and high-income consumers, and educated workers - groups that are considered to be "doing well." Low-skilled native workers are the most adversely affected as competition with immigrants lowers their wages. Second, low-income immigrants with families who use more in public services than they pay in taxes put an enormous fiscal burden on the governments and this cost may outweigh the economic benefit of immigration to the society.

\section{Re-migration}

Molina and Jewell present an analysis of Mexican migrants to the U.S., focusing on their decision to re-migrate. Using data from the Mexican Migration Project, this study analyzes the remigration decision of male, undocumented migrants. In particular, the authors assess the relative importance of various market and nonmarket factors such as income, remittances, and migration networks. It may be noted that the existing literature has shown these factors to be important determinants of initial migration decision. The results of this study indicate that these factors have significant effects on the remigration decision as well. The authors argue that these results have significance for the current migration policy proposals. For example, the authors believe that policies (like the Bush Administration's 2004 proposal) designed to match temporary migrants with U.S. jobs based on skills might lead to more illegal immigration rather than less. From the Mexican perspective, U.S. policies that encourage temporary, repeat migrations will lead to higher remittance flows into Mexico. Therefore, it may be in the best interest of both the U.S. and Mexico to establish bilateral immigration policy. 


\section{Remittances}

The last three articles focus on remittances. Ruiz and Vargas-Silva survey the economics literature that examines causes and consequences of remittances. While Solomon's paper examines how exchange rate uncertainty and political risk affect the flows of remittance transfers into selected Latin American countries, ValeroGil addresses the question if remittance transfers are targeted towards household's healthcare expenditures in Mexico.

\section{Determinants and consequences of remittances: A survey}

Ruiz and Vargas-Silva present an extensive survey of the empirical literature on the determinants and consequences of workers' remittances. It may be noted that the scope of migration and remittances research extends beyond economics and into other social sciences. The survey focuses on the economics literature. There are two main strands of this literature: one is concerned with the factors that determine the flows of remittances, and the other investigates the consequences of remittances. Each of these two strands can further be subdivided into microeconomic studies and macroeconomic studies. The micro studies are mainly based on survey data on various household and migrant characteristics and the macro studies are based on time series or panel data on macroeconomic variables.

The theoretical literature has identified four plausible motives for remittances, namely, altruism - care for family members in home country, self-interests - investment or possibility of inheritance in home country, insurance against risks that migrants are exposed to, and repayment of loans that facilitated migration. Most empirical micro studies examine these motives using data collected through surveys of households and migrants. This paper also discusses the macro level determinants of remittance transfers such as exchange rates, GDP, and interest rates in home as well as host countries that have been examined in the literature. The empirical studies on the determinants of remittances indicate that no single motive for remittances is consistently selected over others across countries and over time.

The literature on the consequences of remittances explores both positive and negative effects of remittances. At the macro level, there is evidence of remittances enhancing economic growth directly through alleviation of credit constraint and an increase in investment or indirectly through an increase in aggregate demand. Among the negative effects, the existing studies provide evidence of appreciation of the local currency in the recipient country, leading to a Dutch disease type phenomenon. The literature also provides evidence of differential effects of remittances 
on prices of different types of goods and services. The impact on the distribution of income has been examined and the results are mixed. The microeconomic studies examine the effects of remittances on the consumption, investment, and savings behavior of remittance receiving households in different countries. The findings cover a wide range of plausible impacts that are discussed in the survey.

\section{Uncertainty and remittances}

Solomon's paper contributes to the strand of literature that examines the determinants of remittances. In particular, she examines the effects of exchange rate uncertainty and political risk, after controlling for the conventional macroeconomic determinants, on remittance transfers into eight Latin American countries between 1990-2006. The results of her empirical analysis suggest that an increase in exchange rate uncertainty reduces remittance flows into these countries. The effect of political risk on remittances is negative but statistically insignificant. Based on these results, the author suggests that governments of the remittance receiving countries can influence the inflow of remittances by means of adopting appropriate macroeconomic policies to reduce exchange rate uncertainty and also by improving their political environments.

\section{Targeted remittances}

Valero-Gil investigates the effect of remittances on household's health expenditures (HHE) and his paper represents a contribution to the literature on the consequences of remittances. By differentiating the effect of remittances on HHE from that of other income sources, this paper examines if remittances are especially targeted towards household's health expenditure in Mexico. The empirical analysis of the data obtained from the National Income Expenditure Survey of Households of Mexico for 2004 reveals that there exists a statistically significant effect of remittances on HHE and that has been interpreted as evidence of targeted remittance transfers. This effect is found to be more pronounced for households without access to the employment's medical insurance.

\section{Notes}

1. See World Bank (2008)

2. The results presented in this paper were a part of the keynote address delivered by Dr. Mauricio Cárdenas, then Executive Director of Fedesarrollo, Bogota, Colombia, 
at the Conference on Regional Trade Agreements, Migration, and Remittances with Special Focus on CAFTA and Latin America on April 12, 2008.

3. This paper has been adapted from the invited lecture delivered by Dr. Pia Orrenius, Senior Economist and Policy Advisor at the Federal Reserve Bank of Dallas, at the Conference on Regional Trade Agreements, Migration, and Remittances with Special Focus on CAFTA and Latin America on April 12, 2008.

\section{Reference}

World Bank. (2008). Migration and Remittances Factbook 2008. Washington, DC: econ.worldbank.org/WBSITE/EXTERNAL/EXTDEC/EXTDECPROSPECTS $/ 0$, contentMDK:21352016 pagePK:64165401 piPK:64165026 theSitePK:476 $883,00 . \mathrm{html}$ 
Journal of Business Strategies 